\title{
Students' peer relationships and their contribution to university adjustment: the need to belong in the university community
}

Rachel E. Maunder

The University of Northampton, England

Address for correspondence: Division of Psychology, School of Social Sciences, University of Northampton, Boughton Green Road, Northampton, NN2 7AL, England, Rachel.Maunder@northampton.ac.uk

Tel: +44 (0)1604 893727 


\title{
Students' peer relationships and their contribution to university adjustment: the need to belong in the university community
}

\begin{abstract}
Whilst new friendships and an active social life are commonly discussed features of 'being a student', there is limited empirical research that has quantitatively studied the contribution that social factors play in students' university experience. Research that has been conducted shows that belonging and social integration are important factors in successful transition to university, and subsequent retention (Pittman and Richmond 2008; Wilcox et al 2005). This paper presents research into students' social relationships at university, their attachment to the university, and how these elements link to university adjustment. Undergraduates $(n=135)$ completed questionnaires measuring their attachment to university peers, attachment to the university, experiences of problematic peer relationships, and quality of adjustment to university life. Students who reported strong attachment with their peers also had higher levels of university adjustment and university attachment. Students who reported difficulties in their relationships with other students had lower levels of peer attachment and university adjustment. Attachment to university peers was the strongest predictor of university adjustment, followed by attachment to the university. The research highlights the role of social relationships in institutional belonging, and the importance of nurturing peer relationships and institutional affiliation for a positive student experience.
\end{abstract}

Keywords: transition; university; higher education; peer relationships; attachment; belonging 


\section{Introduction}

Starting university can be a turbulent time, due to the need for students to adjust to a new and unfamiliar environment. There are different academic demands, new roles and learner identities to be negotiated, and separation from established relationships with family and friends (Hussey and Smith 2010). It is therefore unsurprising that there is an accumulation of literature studying transition to university in order to understand how students navigate the process. Whilst a lot of research attention has been given to first year students during initial orientation (e.g. Harvey, Drew and Smith 2006; Yorke and Longden 2008), adjusting to higher education is a long process of ongoing change not just limited to starting university (Maunder, Cunliffe, Galvin, Mjali and Rogers 2013; Tobolowsky 2008).

Much of our knowledge about transition comes from studying early withdrawals. Research suggests that causes of attrition are multifaceted (Yorke and Longden 2008), encompassing both individual and institutional elements. Reasons given by students vary depending on the stage of degree and timing in the academic year (Willcoxson 2010), but typical explanations for early withdrawals include a mismatch between expectations and reality (Cook and Leckey 1999), lack of preparedness for university study (Lowe and Cooke 2003), and the quality of teaching and academic support (Willcoxson 2010). Reported difficulties with social relationships such as loneliness and lack of social integration also contribute to attrition (Wilcox, Winn and Fyvie-Gauld 2005; Yorke and Longden 2008; Thomas, 2012). It seems therefore that institutional experiences at the academic and social level impact on the extent to which individuals become integrated into the university (Tinto 1993). Students who do not feel connected to the institution, and feel like they do not 'belong' there, are at risk of drop-out (Tinto, 1993; Thomas, 2012). The purpose of this research therefore is to study directly the relationship between students' social integration, belonging and quality of adjustment to university life.

\section{Belonging at university}

'Belonging' refers to the extent to which students feel valued, accepted and included (Goodenow 1993a), and it can be facilitated through social, academic and professional interactions 
(Parkes 2014). Whilst language varies, terms typically used to describe belonging include membership, connectedness, and attachment to the learning environment (Libbey 2004). This feeling of belonging is important for positive educational experiences. It is linked to children's well-being, motivation, and achievement in schools (e.g. see Goodenow 1993a; 1993b; Libbey 2004; Osterman 2000), and there is developing research exploring this in higher education contexts (e.g. France, Finney and Swerdzewski 2010; Freeman, Anderman and Jensen 2007; Pittman and Richmond 2008; Thomas, 2012).

The need to belong is fundamental, and to achieve this people have an urge to establish and maintain strong and stable interpersonal attachments with others (Baumeister and Leary 1995). Attachment, defined as an "enduring affectional bond of substantial intensity" (Armsden and Greenberg 1987, 428), brings security, and alleviates anxiety and uncertainty. Starting university can be unsettling - stimulating the need for students to forge social connections in order to find their place in the new environment, provide a supportive base, and feel integrated (Scanlon et al. 2007). This need to belong and identify with others is urgent and anxiety provoking for new students, and making initial social contacts is central to them feeling part of university life (Maunder et al. 2013; Wilcox et al. 2005). As students find their feet, these early and often superficial social relationships shift and develop into deeper friendships that provide a more enduring secure base (Maunder et al. 2013; Wilcox et al. 2005). In support of this, Pittman and Richmond (2008) found a strong positive relationship between friendship quality and university belonging at two time points (autumn and spring term) during first year transition. It seems that meaningful social involvement matters, and provides students with valuable social and emotional support during the period of adjustment to university (Tinto 1993; Wilcox et al. 2005). These findings also suggest that the adjustment period is progressive, and not limited just to the first term. For example, Cook and Rushton (2008) recommend extended induction for students throughout their first year, and Tobolowsky (2008) argues for increased attention on transition points at other stages of university study. Moving between the stages of a degree programme involves differing demands and changing academic expectations. Students are 
therefore likely to experience ongoing transitions as they encounter new ideas and processes during their academic career (Rushton and Cook, 2006).

\section{Difficult social relationships at university}

If attachments through friendships and peer support underpins successful university transition (e.g. Kantanis 2001; Harvey, Drew and Smith 2006), it should follow that students who struggle with their peer relationships at university may have difficulties adjusting. Indeed, research shows isolation, loneliness and poor social integration identified as common reasons for attrition (Jones, 2008; Wilcox et al. 2005; Yorke and Longden 2008; Thomas, 2012). In addition, there is evidence that some students experience problematic relationships with their university peers. Sinkkonen, Puhakka and Meriläinen (2014) report that 5\% of students at a Finnish university claimed to have been bullied on campus, and a report in the UK by the National Union of Students stated that $7 \%$ of students have experienced bullying at University (NUS 2008). Such unpleasant experiences will undoubtedly impact on their feelings towards university, and feelings of integration. Being isolated, and not having support to draw on has repercussions for academic engagement, and feelings towards the institution (Kantanis 2001). The very limited research into bullying experiences between university students makes it difficult to draw conclusions however (Coleyshaw 2010), and there is a need for further work in this area in order to understand what role problematic relationships with peers might have on university adjustment.

\section{University attachment}

The review so far indicates that effective social integration with university peers provides one way in which feelings of belonging can be enhanced (Freeman et al. 2007), thus contributing to successful transition. However, university belonging is a broader construct than this, and also refers to the extent to which students identify with and commit to their institution. France et al. (2010) describe this as 'university attachment' whereby students are affiliated with their institution, and feel connected to it. Social relationships with peers can help students develop university attachment (France et al. 2010; Li, Hanson Frieze, Nokes-Malach, and Cheong 2013), but they are separate 
elements meaning that individuals can have one without the other. For example, a student could have lots of friends at university to whom they feel attached, but not feel strongly bonded to the institution, whereas another student could feel proud of their university and identify themselves as a member despite not having meaningful friendships with their peers. France et al. (2010) therefore distinguish between group and member attachment as separate dimensions of university attachment, whereby group attachment refers to attachment to the university as a whole (such as openly identifying as being part of the institution, promoting it, and seeing themselves as a typical student there), and member attachment refers to attachments to the people within the university (such as having lots of friends at university, and feeling close to them). This distinction is based on social identity research which has shown that individuals can develop attachment to a group despite having little or no contact with the other people in the group (see Tajfel 1981).

Attachment to the university and attachment to peers within the university are likely to be mutually entwined to create a sense of belonging which facilitates adjustment to university life. One could suggest that students who have strong peer relationships in addition to high university attachment would be the best adjusted to university compared to those who may only be strong on one aspect, or neither. However, limited research has tested these elements together in order to measure their relative contribution to university adjustment. This knowledge is important, because if it can be shown that peer attachment and university attachment mutually contribute to successful transition, it provides institutions with the impetus to address these aspects directly in order to improve retention, and students' learning experience. Retention is a key priority for institutions not least because early withdrawals from courses and non-completion have funding, reputational and ethical implications (Thomas, 2012). A synthesis of research in the UK has indicated that institutions in the post-92 sector, and factors such as lower entry tariffs, are associated with lower retention figures (Jones, 2008). The institution where this study was conducted meets these 'vulnerability' criteria, and thus had retention high on the agenda. The impetus for this research therefore was to understand factors contributing to successful adjustment within the institution as part of strategic planning to inform subsequent transition support. 


\section{The present study}

Overall, research suggests that attachment to university, and good attachments with peers contribute to university belonging. Feelings of belonging facilitate successful adjustment to university and likely retention, whereas problematic peer relationships disrupt transition. Whilst these connections can be inferred from previous research, there is no existing recent work in a UK context that has examined the interrelationships between these dimensions within the same study in order to explicate this clearly. Higher education provision varies greatly internationally, and between individual institutions, so applicability of findings cannot be assumed. Pittman and Richmond's (2008) study in the US provided evidence for the role of university belonging and friendship quality in university adjustment, but the authors argued for further research in order to ascertain the applicability of findings to different samples and institutions. In addition, France et al.'s (2010) exploration of university attachment (also based in the US) provided initial insight into the potential role of this construct in the student experience, but it has not been directly studied in relation to peer relationships and university adjustment. Therefore, the aim of this study is to investigate the relationships between peer attachment, problematic peer relationships, university attachment and adjustment to university in a UK post-92 setting, in order to ascertain the relative contribution of peer relationships and university attachment to overall university adjustment. Based on the literature thus far, it would be predicted that students who have higher levels of peer attachment and university attachment will be better adjusted to university. In addition, it would be predicted that students who have experienced problematic relationships with their university peers (such as isolation or bullying) would have lower attachment to the university and poorer university adjustment.

\section{Method}

\section{Participants}

135 social science undergraduate students from a university in England participated. The university was a medium sized campus-based modern university in the post-92 sector that is teaching- 
focused, with a strong widening participation agenda. Students were studying various subjects including Psychology ( $n=72)$, Criminology $(n=26)$, joint honours $(n=34)$ and Law $(n=3)$. They were predominantly studying full time $(n=133)$, and a higher proportion of students had moved away from home to attend university $(n=88,65.7 \%)$. Social sciences students were sampled because this academic school were specifically focusing on student retention and transition support at the time so the research aligned with school-level priorities. The students were selected through opportunity sampling by visiting seminar and lecture classes over a two week period and inviting participation. Table 1 shows the student demographics in terms of gender and year group. Based on average enrolment figures for the institution, the sample represented approximately $24 \%$ of the student body in this academic school. Precise response rates by student group and class were unfortunately not obtained and could not be accessed retrospectively due to the nature of the sampling strategy employed. The sample represented all three undergraduate year groups, but was more heavily represented by first year students, and females. Although statistical data shows a higher proportion of females studying at undergraduate level compared to males (HESA 2014), this gender distribution is slightly more pronounced but is typical of the student demographic studying Social Sciences disciplines at this particular institution. Students from all three year groups were recruited to reflect the ongoing adjustment to university at differing stages of degree study.

Insert Table 1 here

\section{Measures}

In order to measure the variables of interest, existing validated scales were used where available to ensure satisfactory psychometric properties and to enable easier comparison between findings in any subsequent replication studies.

\section{College Adaptation Questionnaire (CAQ) (Crombag 1968, cited in Van Roojen 1986).}

The CAQ measures how well students have adjusted to university life. The self-report survey consists of 18 items, eight referring to good adjustment (for example, 'I am very satisfied with the course of my studies') and ten referring to poor adjustment (for example, 'Sometimes I want to give it 
all up'). Students respond on a seven-point scale how applicable the statement is to them, from one (not applicable) to seven (very applicable). Various studies have used this scale to measure university adaptation (e.g. Collings, Swanson and Watkins, 2014) and good internal reliability and construct validity are reported (Van Roojen 1986). The scale was used in its original (English version) form in this study, and the Cronbach's alpha was .90 .

University Attachment Scale (UAS) (France et al, 2010).

The UAS measures attachment to university through two dimensions: attachment to a group (i.e. the university as a whole), and attachment to members of that group (i.e. people within the university). Some studies have used Goodenow's (1993b) Psychological Sense of School Membership Scale (e.g. Pittman and Redmond, 2008) to measure university belonging, but this scale has mainly been tested with high school students rather than university students so it was felt not to be as suitable in this case. University attachment as a construct is relatively new, and the UAS was the only measure the author could find focusing specifically on university students. The decision to use the scale was also based on the direct intention to build on France et al's (2010) previous work on university attachment, and the two dimensions of group and member attachment.

The UAS has nine items, six referring to group attachment and three relating to member attachment. Each item has a five-point response dependent on the question being asked. Example items include, for group attachment: How often do you acknowledge the fact that you are a member of (named university)? (Never; Rarely; About half the time; Most of the time; Always); and for member attachment: How close do you feel to other members of the (named university) community? (Not at all close, Slightly, Moderately, Very, Extremely close). The name of the University was inserted into the appropriate place on each question to make it personal and relevant, but the rest of the scale remained unchanged.

The UAS has not yet been widely used, but when tested on 706 students, 'promising' psychometric properties were reported (France et al, 2010). In this study, internal consistency of the 
overall scale was .85 , for the group attachment scale (6 items) .86 and for the member attachment scale (3 items) .63.

Adapted Inventory of Parent and Peer Attachment (Armsden and Greenberg 1987).

The IPPA is a well-established measure of late adolescents' attachment to parents and peers. Whilst the scale is typically used with adolescents, it has also been tested with college students (Armsden and Greenberg 1987). The full scale consists of two sections: attachment to parents and attachment to peers. Only the peer attachment part of the scale ( 25 statements) was used for this study. Each statement is followed by five response items (almost always or always true, often true, sometimes true, seldom true, or almost never or never true) and there are a mixture of positively and negatively worded items. The authors report favourable internal reliability of the peer section of the IPPA scale, and good test-retest reliability (Armsden and Greenberg 1987). The measure has also been widely used in other studies, including Pittman and Richmond (2008) which provided the basis for this research.

In this study, the wording of the questions was modified to ensure that respondents were thinking only about their university friends when answering the questions, rather than their friends in general. For example, the item 'My friends accept me as I am' was amended to 'My university friends accept me as I am' and the item 'I wish I had different friends' was reworded to 'I wish I had different University friends'. The need for students to consider only their university friends was also emphasised in the questionnaire instructions. Despite these minor amendments to the scale, internal consistency was still very high (.92) indicating that the wording changes did not affect the psychometric properties. The rest of the scale was used in its original form.

\section{Problematic Peer Relationships (PPR).}

In order to measure students' experiences of problematic relationships with their university peers, a series of questions were constructed for the purposes of this study due to there not being an appropriate existing scale available. The questions were introduced to respondents as investigating experiences of 'difficult relationships at university', and were focussed on three areas: conflict, social 
isolation and bullying. For each area, students were asked how often they had experienced that particular difficulty (for example: 'How often have you personally felt socially isolated by other students?'), to which they responded on a five-point scale ranging from 'never' to 'all the time'). They were then asked how serious they regarded the experience to be (rated on a five-point scale from 'not serious' to 'very serious'). Frequency and seriousness ratings for each area were summed to calculate an overall score. Internal consistency for this scale was .77.

\section{Procedure}

The materials and study procedures were approved in advance by the University Ethics Committee. The four measures were included as separate questionnaires in a booklet, with each section introducing the aim of that questionnaire and explaining how to respond. Demographic questions about participants' gender, year group, and age category were also included at the start. Each questionnaire booklet had a removable information sheet on the front detailing the aims and purpose of the study, and outlining ethical issues around consent, withdrawal, and storage of data. There was also a tick-box consent form confirming their willingness to participate. A participant number was included to enable participants to withdraw their data at a later stage, but no participants withdrew. Participants remained anonymous throughout, and they could exclude any questions they did not want to answer.

Data was collected over a two week period during the spring term prior to the Easter break. The researcher visited lecture and seminar classes across all three undergraduate year groups to invite participation. Participants either completed the questionnaires in class, or took them away and returned them at a later stage.

\section{Results}

Table 2 reports descriptive statistics showing the mean and spread of scores for each measure. The mean University Adjustment score (measured through the CAQ) was above the scale midpoint 
showing that students were, on average, well adjusted to university life. There was quite high variability however with scores ranging from 42 to 126 , showing that some students had much lower adjustment. Peer Attachment to university friends (measured through the adapted IPPA) also showed mean scores above the midpoint of the scale, although the high standard deviation indicated variability in scores. Average University Attachment (measured through the UAS) was towards the upper end of the scale, with moderate variability in scores. The scores for Problematic Peer Relationships (measured through the PPR scale) were generally low, indicating that most students did not report experiencing many difficulties in their relationships with university peers. There were however a minority of students who did report problematic experiences which might give cause for concern. Overall scores ranged from the minimum of three up to 20, which suggested a high level of difficulties for some students. A number of respondents $(n=47)$ left this section blank, and it is unclear whether this was because they had no negative experiences to report or whether they chose not to disclose. Either way, it is likely that difficult experiences were under-reported. Independent $t$ tests for the CAQ, IPPA, UAS to examine differences in scores between those who completed the PPR and those who left it blank were conducted, but no statistically significant effects were found.

Insert Table 2 here

The first stage of the analysis involved examining between-group differences to ascertain whether demographic variables influenced responses to the measures. Visual inspection of histograms showed that the distribution of data on main variables were approximately normal hence suitable for parametric testing. Table 3 shows that there were no significant differences in scores on any of the measures between year groups, course groups or between traditional and mature students. There were also no significant differences in scores on any of the measures between males and females, with the exception of Member Attachment where males $(\bar{X}=9.25, s d=2.03)$ scored higher than females $(\bar{X}=8.19, s d=2.24)$. However, when Bonferroni correction was applied to account for multiple testing, this result was no longer statistically significant. The effect size was also not large. To account for the unequal sample sizes between groups, parametric tests were re-run with non-parametric analysis where equal variances were not assumed, but no differences in the identified statistical 
significant findings were noted. Due to the lack of between-group differences identified, and small effect sizes, analysis continued with all participants' results combined together.

Insert Table 3 here

Table 4 shows the correlations (Pearsons $r$ ) between the various measures. As predicted, University Adjustment correlated strongly with University Attachment and Peer Attachment, meaning that as Peer Attachment and University Attachment increased, so too did University Adjustment. A negative correlation was found between University Adjustment and Problematic Peer Relationships, showing that as the frequency and seriousness of reported peer relationship problems increased, the level of University Adjustment decreased. Problematic Peer Relationships also correlated negatively with Peer Attachment, but was not correlated with University Attachment to a statistically significant level, even through the trends were in the expected direction. When University Attachment was broken into subscales, both Group Attachment and Member Attachment were positively correlated with University Adjustment and Peer Attachment.

\section{Insert Table 4 here}

Hierarchical linear regression was conducted to see which variables could effectively predict University Adjustment. Based on previous research showing that good relationships with peers are important contributors of successful adjustment, Peer Attachment was entered into the model first. University Attachment was entered into the model second, and with Problematic Peer Relationships being a newer area of study, this was entered into the model last (Table 5).

\section{Insert Table 5 here}

Model 1 showed that $48 \%$ of the variance in University Adjustment could be explained by Peer Attachment $(F(1,85)=77.02, p<.001)$. When University Attachment was also added (model 2$)$, the variance explained increased to $55 \%$ and significantly improved the predictive ability of the model, even though the overall $\mathrm{F}$ value decreased $(F(2,84)=50.54, p<.001)$. Although adding Problematic Peer Relationships (model 3) did still produce a statistically significant regression model 
$(F(3,83)=34.721, p<.001)$ and increased the variance explained, this increase was only slight and was not a significant improvement to the model. Model 1 and 2 both significantly improved the ability to predict University Adjustment (compared to error), but the F change and $\mathrm{F}$ ratio were higher for model 1 suggesting it was the strongest model. Standardized coefficients showed that Peer Attachment was indeed a stronger predictor of University Adjustment than University Attachment $($ Peer attachment $=.52$; University attachment $=.32)$ but both were positively and significantly related to University Adjustment. University Attachment does contribute to predicting University Adjustment - just to a slightly lesser extent than Peer Attachment.

To assess the contribution of the two separate dimensions of University Attachment (Group and Member Attachment), hierarchical linear regression was re-run with Peer Attachment, Group Attachment and Member Attachment added as predictor variables in turn (see Table 6). The $42 \%$ variance explained in University Adjustment by Peer Attachment alone (model 1) increased by 11\% when Group Attachment was added $(\operatorname{model} 2)(F(2,130)=71.71, p<.001, \mathrm{~F}$ change $=28.64)$. In model 3, adding Member Attachment did not increase the variance explained, and the F change was non-significant. Standardized coefficients showed that Peer Attachment was a stronger predictor of University Adjustment compared to Group or Member Attachment (Peer attachment $=.49$; Group Attachment $=.32$; Member Attachment $=.08)$. Although Member Attachment correlated with University Adjustment, it did not contribute significantly to the overall regression model. This suggests that Group Attachment is the strongest element of University Attachment when predicting University Adjustment.

Insert Table 6 here

\section{Discussion}

Results showed that adjustment to university was related to how attached students were to their university friends. Students who had stronger relationships with university peers had higher levels of adjustment to university, whereas students who reported to experience problematic 
relationships had lower adjustment. Attachment to the university was also related to adjustment, with students who had stronger attachment to the institution reporting higher university adjustment. Group attachment (to the university as a whole) was more strongly related to adjustment than member attachment (to people within the university). Overall, the strongest predictor of university adjustment was the attachment students had to their university friends. University attachment also contributed to university adjustment, but to a lesser extent than peer attachment.

The considerable contribution of peer attachment towards university friends in reported university adjustment mirrors findings from previous international literature, and suggests it can be applied to a UK post-92 setting. Results indicate that social relationships with peers are a key part of transition to university, and students who form good quality friendships with their peers are better adjusted to university life (Tinto 1993; Pittman and Richmond 2008; Wilcox et al. 2005; Kantanis 2001). The fact that no statistically significant differences in university adjustment, attachment or peer attachment were found between students in each year group was interesting given the varied duration they had been at university. This further suggests that the transition is not limited to first year, and that variations in adjustment to university, institutional attachment, and peer relationships are still found in second and third year students (Maunder et al. 2013; Tobolowsky 2008).

Although it is not possible to infer direct cause and effect due to the correlational nature of the study, the resonance of these findings with existing qualitative work where students have articulated that forming meaningful social relationships was a causal factor in shaping their transition experiences (Maunder et al. 2013; Wilcox et al. 2005) helps to interpret the likely direction of the relationship. Tinto's (1993) model of student retention also emphasises the need for effective integration into the university, whereby social integration through friendship and positive peer interactions is a central aspect in fostering commitment and belonging to the university community. This reinforces the need for higher education institutions to take students' social experience at university seriously, and actively encourage friendship development in the early stages (Leese 2010; Maunder et al. 2013). This could include structured group activities during classes, organised social events and opportunities for regular discussion and collaboration (e.g. Thomas and Hanson 2014; 
Peat, Dalziel and Grant 2001). For example, in the institution where this study was conducted, the findings fed into school-level initiatives such as a student mentoring scheme, and increased focus on social activities during induction periods (in each year of study).

Students' feelings of social acceptance are associated with their sense of belonging to the university (Freeman et al. 2007), and results from this study support this trend as shown by the significant relationship between peer attachment and university attachment. Students with strong attachments to their university friends had stronger attachment to the university as a whole. Results also found university attachment to be a significant predictor of university adjustment, although its contribution was less strong than peer attachment. Feelings of attachment are closely aligned to notions of belonging and connectedness, whereby students feel that they 'fit' to the institution (France et al. 2010; Wilson and Gore 2013). During students' struggle to form a new identity during transition (Scanlon et al. 2007), having an affinity with their university, and identifying themselves as a member contributes to their sense of belonging (Freeman et al. 2007). Higher attachment to the university can be beneficial for students' learning too, because their affinity and positive feelings towards it may increase likely involvement in institutional activities and heighten personal responsibility towards wanting to succeed there ( $\mathrm{Li}$ et al. 2013). Therefore it seems pertinent for institutions to seek ways of instilling students' attachment to university from the outset to help them establish belonging - thus smoothing transition. Li et al. (2013) recommend initiating 'attaching behaviours' (p.142) to facilitate students' affiliation to their university, including promoting membership and support for university teams and societies, following and sharing news about the university and collecting souvenirs or branded items.

When the separate dimensions of university attachment were considered individually, results indicated that group attachment was more important than member attachment in predicting university adjustment. Initially this was surprising because member attachment refers to how attached students feel to people within the university, making it more closely aligned to peer attachment which has already emerged as the main contributor to university adjustment. Indeed, member attachment correlated more highly with peer attachment than the other measures (with the exception of university 
adjustment) - suggesting that the constructs were related. In addition, peer attachment and member attachment overlapped conceptually given their shared focus on peer relationships and friendships. However, there was no multicollinearity between these variables, and the content of the questions in the scales had a different focus. The peer attachment scale from the IPPA measured in detail the nature and quality of participants' friendships with peers, whereas the member attachment scale referred more generally to members of the university community (which could include fellow students, lecturers or others), and asked broader questions about how close these relationships were. This differing emphasis may begin to explain why member attachment performed differently to peer attachment when predicting university adjustment. It seems that the quality of relationships with university peers (as measured through the peer attachment scale) is important, and perhaps needs more emphasis in the member attachment scale in order to effectively capture this aspect of students' experience. In its current form, the UAS includes only three questions to measure member attachment, compared to six measuring group attachment. Also, the internal consistency was notably lower for the member attachment subscale compared to group attachment (.63 and .86 respectively). The member attachment dimension, in its current form, did not make a significant contribution to the regression model, despite predictions that it should given the evidence pointing to the important role of students' relations with others at university in predicting adjustment. Given that group and member attachment performed differently in the analysis, the findings add weight to the notion of separate dimensions to university attachment (France et al. 2010). However, the results do indicate that further attention needs to be given to the member attachment dimension, and how it is measured. Using existing scales in this study to measure the variables facilitates subsequent research aiming to replicate results, and further examine the constructs of interest in other institutions and contexts. For example, it would be interesting to see how the UAS performs in a follow-up study, and whether similar findings are reported about the relative contribution of group versus member attachment.

If, as the results suggest, university belonging includes both social integration with peers alongside connection to the institution, it should follow that students who do not integrate in this way are at risk of disaffection and possible attrition (Tinto 1993). In support of this, results showed 
negative correlations between the occurrence of problematic peer relationships and overall university adjustment. This shows that failure to integrate socially with peers is associated with poorer transition. In the subsequent regression analysis, problematic peer relationships did contribute towards predicting university adjustment in the predicted direction, but to a much lesser extent than the other variables and did not significantly improve the model. One possible explanation for this could be that the experience of positive peer relations is more important in predicting adjustment to university when compared to the experience of negative peer relations. For example, there is evidence showing the value of close friendship and social support for building resilience, and enabling individuals to deal more effectively with change (see Burt and Paysnick 2012). However, further work is needed before conclusions are drawn. The Problematic Peer Relationships (PPR) measure may need further development to confirm the scale's reliability and validity. In its current form, it measured experiences of bullying, conflict and social isolation in one scale and whilst there are likely to be overlaps between these experiences (for example, a student who is bullied by their peers is likely to also feel socially isolated), they may also manifest themselves differently and have differential effects. Therefore it would be sensible to explore measuring each aspect separately, and in more detail, in order to understand if some problematic experiences have more impact on university adjustment than others.

In addition, a notable proportion of students (approximately 50 from the sample of 133) did not fully complete the PPR scale, despite completing the other measures. It is not clear whether this was because they did not feel that the questions were relevant for them, or if they felt uncomfortable answering them. The 'hidden' nature of bullying in higher education (Coleyshaw 2010) could be particularly relevant here, and warrants additional scrutiny - possibly with follow-up interviews with students or the inclusion of some open-ended questions to enquire in more detail about their experiences. A qualitative approach may be more appropriate for examining sensitive topics such as bullying.

For those who did complete the PPR, average scores were quite low - suggesting a low occurrence of problematic relationships across the sample. There is however likely to be 
underreporting of the issue, either through students choosing not to answer that section of the questionnaire, or from them not being in attendance at university to participate in the research. A limitation of this study is that data was only collected from students who were in class when the researcher visited. Students who attend classes are likely to be more actively engaged with their studies (Newman-Ford, Fitzgibbon, Lloyd and Thomas 2008), and non-attendance can be a warning sign of disaffection and possible later withdrawal from university (Bowen, Price, Lloyd and Thomas 2005). Therefore, it is likely that students who were experiencing problems with their peer relationships and/or their transition to university would be less likely to be in attendance to have the chance to participate in the research. As a result, it is possible that the sample for this study was biased towards students who were more positively integrated with their university peers and who had transitioned successfully. It is notoriously difficult to access disengaged students, but it would be recommended that further research seeks ways to reach this vulnerable group to ensure their experiences are represented and fully understood. Online questionnaires may be one way to access students not attending campus regularly. Additionally, obtaining more precise response rates at the point of data collection would have enabled detailed understanding of the student profile of those who did and did not participate in the study. It would also help to ensure that more equal between-group samples were obtained (for example, recruiting more males, and a more balanced representation by course group).

In conclusion, the research found that peer attachment and university attachment predicted university adjustment. Therefore, institutions wanting to improve students' transition experiences and outcomes would be encouraged to seek ways of helping students to form meaningful social connections with their peers from the outset, and also establish a sense of institutional identity and membership. The results add further support to the existing literature showing links between students' social relationships with university peers, their sense of belonging to the institution and how these aspects contribute to university adjustment. The study also highlights the value of the "university attachment' construct as a relatively new area of study in higher education (France et al. 2010) although further research may be needed to establish a robust measure. Additional research in 
different types of institutions and varied higher education contexts will add credence to the transferability of the findings.

\section{References}

Armsden, G. G. and Greenberg, M. T. 1987. “The Inventory of Parent and Peer Attachment: individual differences and their relationship to psychological well-being in adolescence". Journal of Youth and Adolescence, 16 (5): 427-454.

Baumeister, R. F. and Leary, M. R. 1995. "The need to belong: desire for interpersonal attachments as a fundamental human motivation”. Psychological Bulletin, 17 (3): 497-529.

Bowen, E., Price, T., Lloyd, S. and Thomas, S. 2005. "Improving the quantity and quality of attendance data to enhance student retention". Journal of Further and Higher Education, 29 (4): $375-385$.

Burt, K. B. and Paysnick, A. A. 2012. "Resilience in the transition to adulthood". Development and Psychopathology, 24: 493-505.

Coleyshaw, L. 2010. "The power of paradigms: a discussion of the absence of bullying research in the context of the university student experience". Research in Post-Compulsory Education, 15 (4): $377-386$.

Collings, R., Swanson, V. and Watkins, R. 2014. "The impact of peer mentoring on levels of student wellbeing, integration and retention: a controlled comparative evaluation of residential students in higher education". Higher Education, 68 (6): 927-942. 
Cook, A. and Leckey, J. 1999. "Do expectations meet reality? A survey of changes in first-year student opinion". Journal of Further and Higher Education, 23 (2): 157-171.

Cook, A. and Rushton, B., 2008. Student Transition: Practices \& policies to promote Retention. UK: Staff \& Educational Development Association.

Crombag, H. F. M. 1968. Studie motivatie en studie attitude. Groningen: Walters.

France, M. K., Finney, S. J. and Swerdzewski, P. 2010. “Students' group and member attachment to their university: a construct validity study of the University Attachment Scale”. Educational and Psychological Measurement, 70 (3): 440-458.

Freeman, T. M., Anderman, L. H. and Jensen, J. M. 2007. "Sense of belonging in college freshmen at the classroom and campus levels". The Journal of Experimental Education, 75 (3): 203-220.

Goodenow, C. 1993a. "Classroom belonging among early adolescent students: relationships to motivation and achievement". Journal of Early Adolescence, 13 (1): 21-43.

Goodenow, C. 1993b. "The psychological sense of school membership among adolescents: scale development and educational correlates". Psychology in the Schools, 30 (1): 79-90.

Harvey, L., Drew, S. and Smith, M. 2006. The first-year experience: a review of literature for the Higher Education Academy. Higher Education Academy Publication.

HESA 2014. Student Introduction 2012/13. Higher Education Statistics Agency. Data available from: https://www.hesa.ac.uk/content/view/3129/\#sex (accessed 10/11/15) 
Hussey, T., and Smith, P. 2010. "Transitions in higher education". Innovations in Education and Teaching International, 47 (2): 155-164.

Jones, R. (2008). Student retention and success: a synthesis of research. EvidenceNet, Higher Education Academy. Available from: https://www.heacademy.ac.uk/resources/detail/inclusion/wprs/WPRS retention synthesis

Kantanis, T. 2000. "The role of social transition in students' adjustment to the first-year of university". Journal of Institutional Research, 9 (1): 100-110.

Leese, M. 2010. "Bridging the gap: Supporting student transitions into higher education". Journal of Further and Higher Education, 34 (2): 239-251.

Li, M., Hanson Frieze, I., Nokes-Malach, T. J. and Cheong, J. 2013. "Do friends always help your studies? Mediating processes between social relations and academic motivation". Social Psychology of Education, 16: 129-149.

Libbey, H. P. 2004. “Measuring student relationships to school: attachment, bonding, connectedness and engagement". Journal of School Health, 74 (7): 274-283.

Lowe, H. and Cook, A. 2003. "Mind the gap: are students prepared for higher education?" Journal of Further and Higher Education, 27 (1): 53-76.

Maunder, R., Cunliffe, M., Galvin, J., Mjali, S. and Rogers, J. 2013. "Listening to student voices: student researchers exploring undergraduate experiences of university transition”. Higher Education. 66 (2): 139-152. 
Newman-Ford, L., Fitzgibbon, K., Lloyd, S. and Thomas, S. 2008. "A large-scale investigation between attendance and attainment: a study using an innovative, electronic attendance monitoring system". Studies in Higher Education, 33 (6): 699-717.

NUS 2008. NUS Student Experience Report. National Union of Students. Retrieved November 18, 2014, from http://www.nus.org.uk/PageFiles/4017/NUS StudentExperienceReport.pdf

Osterman, K. F. 2000. "Students' need for belonging in the school community". Review of Educational Research, 70 (3): 323-367.

Parkes, S. 2014. "Fostering a sense of belonging: supporting the early formation of student identity as successful learners in higher education". Journal of Learning Development in Higher Education, 7 (June): 1-22.

Peat, M., Dalziel, J. and Grant, A. M. 2001. "Enhancing the first year student experience by facilitating the development of peer networks through a one-day workshop". Higher Education Research \& Development, 20 (2): 199-215.

Pittman, L. D. and Richmond, A. 2008. "University belonging, friendship quality and psychological adjustment during the transition to college". The Journal of Experimental Education, 76 (4): 343361.

Rushton, B. R. and Cook, A. (2006). "STAR Glossary". Chapter 6 in Student Transition and Retention (STAR), edited by A. Cook, B. S. Rushton and K. A. Macintosh, 77-91. University of Ulster. 
Scanlon, L., Rowling, L. and Weber, Z. 2007. “'You don't have like an identity....you are just lost in a crowd': Forming a student identity in the first-year transition to university". Journal of Youth Studies, 10 (2): 223-241.

Sinkkonen, H., Puhakka, H. and Meriläinen, M. 2014. "Bullying at a university: students' experiences of bullying”. Studies in Higher Education, 39 (1): 153-165.

Tajfel, H. 1981. Human groups and social categories: studies in social psychology. Cambridge, UK: Cambridge University Press.

Thomas, L. (2012). Building student engagement and belonging in Higher Education at a time of change: a summary of findings and recommendations from the What Works? Student Retention \& Success programme. London: Paul Hamlyn Foundation.

Thomas, B. G. and Hanson, J. 2014. "Developing social integration to enhance student retention and success in higher education: the GROW@BU initiative”. Widening Participation and Lifelong Learning, 16 (3): 58-70.

Tinto, V. 1993. Leaving College: Rethinking the causes and cures of student attrition (2nd ed). Chicago: University of Chicago Press.

Tobolowsky, B. F. 2008. “Sophomores in transition: The forgotten year”. New Directions for Higher Education, 144: 59-67.

Van Roojen, L. 1986. “Advanced students' adaptation to college”. Higher Education, 15: 197-209. 
Wilcox, P., Winn, S. and Fyvie-Gauld, M. 2005. "“It was nothing to do with the university, it was just the people': the role of social support in the first year experience of higher education". Studies in Higher Education, 30 (6): 707-722.

Willcoxson, L. 2010. "Factors affecting intention to leave in the first, second and third year of university studies: A semester-by-semester investigation". Higher Education Research and Development, 29 (6): 623-639.

Wilson, S. and Gore, J. 2013. "An attachment model of university connectedness". The Journal of Experimental Education, 81 (2): 178-198.

Yorke, M., and Longden, B. 2008. The first-year experience of higher education in the UK. England: Higher Education Academy. 
Table 1

Total number of participants based on gender and year group

\begin{tabular}{lccc}
\hline Undergraduate Year group & Males & Females & Total \\
\hline First year & 18 & 69 & 87 \\
Second year & 8 & 14 & 22 \\
Third year & 2 & 24 & 26 \\
Traditional age (18- 21 years) & 24 & 87 & 111 \\
Mature students (> 21 years) & 4 & 20 & 24 \\
Total & 28 & 107 & 135 \\
\hline
\end{tabular}


Table 2

Descriptive statistics for student responses to each measure

\begin{tabular}{|c|c|c|c|c|c|c|c|c|}
\hline Measure & Scale max & Scale min & Sample max & Sample min & $n$ & Mean & $95 \% \mathrm{CI}$ & $s d$ \\
\hline University adjustment (CAQ) & 126 & 18 & 126 & 42 & 135 & 90.80 & $87.86-93.74$ & 17.26 \\
\hline Group attachment subscale & 30 & 6 & 29 & 7 & 135 & 19.16 & $18.36-19.97$ & 4.74 \\
\hline Peer attachment (from IPPA) & 125 & 25 & 124 & 57 & 133 & 99.56 & $97.07-102.06$ & 14.56 \\
\hline Problematic peer relationships (PPR) & 27 & 3 & 20 & 3 & 88 & 7.72 & $6.86-8.59$ & 4.07 \\
\hline
\end{tabular}


Table 3

Between-group differences for each measure

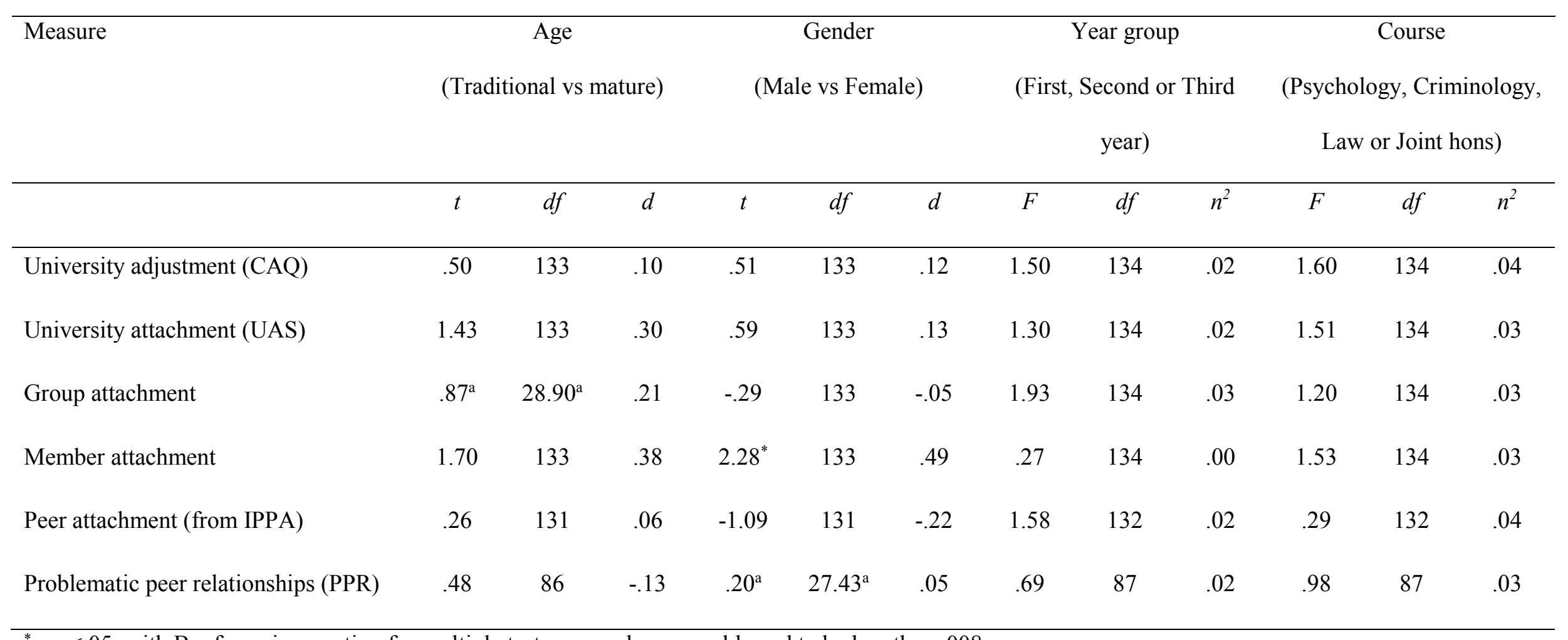

${ }^{*}=p<.05$; with Bonferroni correction for multiple tests on gender, $p$ would need to be less than .008

$\mathrm{a}=$ equal variances not assumed 
Table 4

Correlations between measures

\begin{tabular}{|c|c|c|c|c|c|c|}
\hline Measure & 1 & 2 & 3 & 4 & 5 & 6 \\
\hline 1. University adjustment (CAQ) & 1.00 & & & & & \\
\hline 2. University attachment (UAS) & $.60^{* * *}$ & 1.0 & & & & \\
\hline 3. Group attachment subscale & $.54^{* * *}$ & $.95^{* * *}$ & 1.0 & & & \\
\hline 4. Member attachment subscale & $.49^{* * *}$ & $.74^{* * *}$ & $.49^{* * *}$ & 1.0 & & \\
\hline 5. Peer attachment (from IPPA) & $.65^{* * *}$ & $.48^{* * *}$ & $.37^{* * *}$ & $.54^{* * *}$ & 1.0 & \\
\hline 6. Problematic peer relationships (PPR) & $-.36^{* *}$ & -.19 & -.16 & -.17 & $-.40^{* * *}$ & 1.0 \\
\hline
\end{tabular}

${ }^{*}=p<.05,{ }^{* *}=p<.01,{ }^{* * *}=p<.001$ 
Table 5

Outcomes of hierarchical regression to predict University Adjustment, with Peer Attachment, University Attachment and Problematic Peer Relationships as predictor variables

\begin{tabular}{|c|c|c|c|c|c|c|c|c|c|}
\hline Model & Predictors & $\mathrm{R}^{2}$ & Adjusted $\mathrm{R}^{2}$ & $\mathrm{R}^{2}$ change & F change & $\mathrm{df}$ & $\beta$ & $\mathrm{t}$ & $95 \% \mathrm{CI}$ for $\beta$ \\
\hline 1 & Peer attachment & .48 & .469 & .48 & $77.02^{* * *}$ & 85 & .69 & $8.78^{* * *}$ & $.55-.87$ \\
\hline \multirow[t]{3}{*}{2} & Peer attachment (1) & & & & & & .52 & $5.90^{* * *}$ & $.35-.71$ \\
\hline & & .55 & .535 & .07 & $13.09^{* *}$ & 84 & & & \\
\hline & University Attachment (2) & & & & & & .32 & $3.62^{* *}$ & $.15-.50$ \\
\hline \multirow[t]{6}{*}{3} & Peer Attachment (1) & & & & & & .47 & $5.05^{* * *}$ & $.30-.68$ \\
\hline & University Attachment (2) & & & & & & .32 & $3.67^{* * *}$ & $.15-.50$ \\
\hline & & .56 & .541 & .01 & 1.95 & 83 & & & \\
\hline & Problematic Peer & & & & & & & & \\
\hline & & & & & & & -.11 & -1.39 & $-.28-.05$ \\
\hline & Relationships (3) & & & & & & & & \\
\hline
\end{tabular}


Table 6

Outcomes of hierarchical regression to predict University Adjustment, with Peer Attachment, Member Attachment and Group Attachment as predictor variables

\begin{tabular}{|c|c|c|c|c|c|c|c|c|c|}
\hline Model & Predictors & $\mathrm{R}^{2}$ & Adjusted $\mathrm{R}^{2}$ & $\mathrm{R}^{2}$ change & F change & $\mathrm{df}$ & $\beta$ & $\mathrm{t}$ & $95 \% \mathrm{CI}$ for $\beta$ \\
\hline 1 & Peer attachment & .42 & .42 & .42 & $94.79^{* * *}$ & 131 & .65 & $9.74^{* * *}$ & $.51-.77$ \\
\hline \multirow[t]{3}{*}{2} & Peer attachment (1) & & & & & & .52 & $7.99^{* * *}$ & $.39-.64$ \\
\hline & & .53 & .52 & .11 & $28.64^{* * *}$ & 130 & & & \\
\hline & Group attachment (2) & & & & & & .35 & $5.35^{* *}$ & $.22-.47$ \\
\hline \multirow[t]{3}{*}{3} & Peer attachment (1) & & & & & & .49 & $6.72^{* * *}$ & $.34-.63$ \\
\hline & Group attachment (2) & .53 & .52 & .00 & .94 & 129 & .32 & $4.64^{* * *}$ & $.18-.46$ \\
\hline & Member attachment (3) & & & & & & .08 & .97 & $-.08-.23$ \\
\hline
\end{tabular}

